\title{
Population-wide administration of single dose rifampicin for leprosy prevention in isolated communities: a three year follow-up feasibility study in Indonesia
}

Anuj Tiwari ${ }^{1 *}$ (D, Steaven Dandel ${ }^{2}$, Rita Djupuri ${ }^{3}$, Liesbeth Mieras ${ }^{4}$ and Jan Hendrik Richardus ${ }^{1}$

\begin{abstract}
Background: Indonesia ranking third in the world, regarding leprosy burden. Chemoprophylaxis is effective in reducing risk of developing leprosy among contacts. 'Blanket approach' is an operational strategy for leprosy postexposure prophylaxis in which all members of an isolated community, high endemic for leprosy are screened and given a single dose of rifampicin (SDR) in the absence of signs and symptoms of leprosy. The objective is to assess the operational feasibility of a population-wide 'blanket' administration of SDR for leprosy prevention in isolated communities in a remote island.
\end{abstract}

Methods: A prospective follow-up study was conducted in the year 2014, 2015 and 2016 in Lingat village of Selaru Island, Indonesia. During the first two visits, screening and SDR were provided, whereas only screening was conducted during the third visit. The demographic and clinical data were used for a descriptive analysis of the project coverage and leprosy epidemiology.

Results: During the first two visits, 1671 persons (88\%) were screened, 1499 (79\%) received SDR, and 213 (11\%) were excluded based on the exclusion criteria. During the first two visits, 43 (2.6\%) cases were diagnosed with leprosy with a rate of 2263 per 100,000 population. The prevalence was highest in the age groups 15-24 and 25-49 years. Total, 14 (33\%) cases had MB and 29 (67\%) PB leprosy. Two cases (5\%) had grade 2 disability. During the third visit, 10 new leprosy cases, with no grade 2 disability, were detected out of 1481 screened persons at the rate of 484 cases per 100,000 population ( $n=2065$ population in 2016). Among those screened during the third visit, there was a 50\% reduction of leprosy among those who had previously received SDR compared to those who had not.

Conclusion: With adequate planning and some additional investment, it is feasible to implement a blanket approach of chemoprophylaxis in a remote island of Indonesia, although effort needs to be made to cover as many people as possible in the first visit. Contingency plans need to be made to actively follow this village closely in the coming years and continue leprosy elimination efforts until no new cases are found any more.

Keywords: Leprosy prevention, Single dose rifampicin, Post exposure prophylaxis, Blanket approach, Feasibility

\footnotetext{
*Correspondence: a.tiwari@erasmusmc.nl

1 Department of Public Health, Erasmus MC, University Medical Center

Rotterdam, P.O.Box 2040, 3000, CA, Rotterdam, The Netherlands

Full list of author information is available at the end of the article
}

(c) The Author(s). 2018 Open Access This article is distributed under the terms of the Creative Commons Attribution 4.0 International License (http://creativecommons.org/licenses/by/4.0/), which permits unrestricted use, distribution, and reproduction in any medium, provided you give appropriate credit to the original author(s) and the source, provide a link to the Creative Commons license, and indicate if changes were made. The Creative Commons Public Domain Dedication waiver (http://creativecommons.org/publicdomain/zero/1.0/) applies to the data made available in this article, unless otherwise stated. 


\section{Background}

Leprosy is an infectious disease caused by Mycobacterium leprae [1]. The disease burden has reduced in the last two decades, for which multidrug therapy (MDT) is largely credited $[2,3]$. Unfortunately, this has not led to the incidence based global elimination of leprosy [4]. Currently, 136 countries report leprosy (210,758 new cases in 2015), indicating that transmission of M. leprae has not yet been interrupted [5]. Leprosy causes serious and irreversible nerve damage, which is a leading cause of disability among communicable diseases in developing countries [6]. Globally, 14,059 cases $(0.25 / 100,000$ population) were detected with grade 2 disability in 2015 [5].

Indonesia is an archipelagic island country with a population of 237.6 million [7]. Half of its population lives in rural areas (census 2010) and there are over 300 ethnic groups in the country [8]. The geographical and demographical diversity challenges health service delivery, especially in remote areas [9]. Indonesia contributes $8 \%$ $(17,202$ new cases in 2015) to the global leprosy burden, and ranks third after India and Brazil [5]. The majority (84\%) of new cases have the multibacillary (MB) form of the disease, which is considered largely responsible for the transmission due to high bacterial load. Following intensified efforts by the National Leprosy Control Programme (NLCP) of the Indonesian government, the new case detection rate declined between 2005 and 2014 by $13.5 \%$ [10]. However, a recent modelling study predicted that the 2020 London Declaration target of leprosy elimination in terms of interruption of transmission will be difficult to achieve for Indonesia [11-13]. Stigmatization of leprosy is a severe problem in Indonesia and this also hampers efforts to find and treat leprosy patients [14-16].

Initially, leprosy control and later elimination efforts focused heavily on finding and treating patients [17], but attention is now shifting more towards prevention of the disease. The latest WHO Global Leprosy Strategy 2016-2020 has early case finding (through contact tracing and screening) high on the agenda [18]. Preventive interventions that are currently being considered are chemoprophylaxis and immunoprophylaxis [19]. Chemoprophylaxis or post-exposure prophylaxis (PEP) is often combined with other approaches such as contact tracing or 'blanket' approaches [20, 21]. 'Blanket' approach is a strategy in which all members in a given community are screened by trained health workers for leprosy and given post-exposure prophylaxis (PEP). This approach is potentially suitable for secluded high-endemic areas, such as small islands communities. The leprosy control programme of Indonesia is introducing new prevention methods. It is the first country in Southeast Asia to pilot PEP with a single dose of rifampicin (SDR) within the leprosy control programme for selective highly endemic districts. Indonesia gained valuable experience with contact tracing followed by SDR in Sampang district (East Java), Bima district (West Nusa Tenggara), and the blanket approach in Mumugu village, Papua. These experiences however, have not yet been documented scientifically and disseminated for wider learning. A single but important study from Indonesia concluded that the blanket approach with rifampicin is effective in reducing the incidence of leprosy [22]. It is very important to explore the feasibility and effectiveness of the blanket approach in detail, because the national programme plans to expand SDR to other highly endemic areas, many of them being remote islands.

The blanket approach in Lingat Village was implemented under the Leprosy Post Exposure Prophylaxis (LPEP) programme. The objective of this paper is to assess the operational feasibility of the population-wide 'blanket' administration of SDR for leprosy prevention in isolated communities, by documenting the implementation process and initial results of a pilot project in a remote island of Indonesia.

\section{Methods \\ Intervention site}

The blanket approach was conducted in Lingat village (population around 1900 in year 2014) in three visits in November 2014, November 2015 and November 2016. The village is situated on Selaru Island (Southeast Maluku West), which is a part of Tanimbar Islands in Maluku (Fig. 1).

The village can only be reached by boat and every year, due to poor weather conditions, the village is extremely hard to reach for several months. The NLCP received verbal information from the health workers of Tanimbar Islands that around 30 people were suspected of having leprosy. Photographs of the persons with patches were inspected by a leprosy expert. After initial confirmation, the government and non-governmental partners discussed the feasibility and agreed to organize a PEP blanket campaign. The selection criteria for the blanket approach are listed in Table 1.

\section{Study design}

This is a three year prospective follow-up study, where implementation of the SDR intervention was completed during the first two visits with a year interval. During the third visit, the complete population of the island was screened again to establish the number of new cases arising since the implementation of the intervention during the first two visits. The campaign team first listed households, screened all available individuals and detected new leprosy cases, which were subsequently put on MDT. The remaining eligible population was offered SDR, after checking for the exclusion criteria, i.e. absence from the house, refusing consent, pregnant, suspect of having leprosy or diagnosed with leprosy, history of receiving rifampicin (for leprosy or any other disease) 


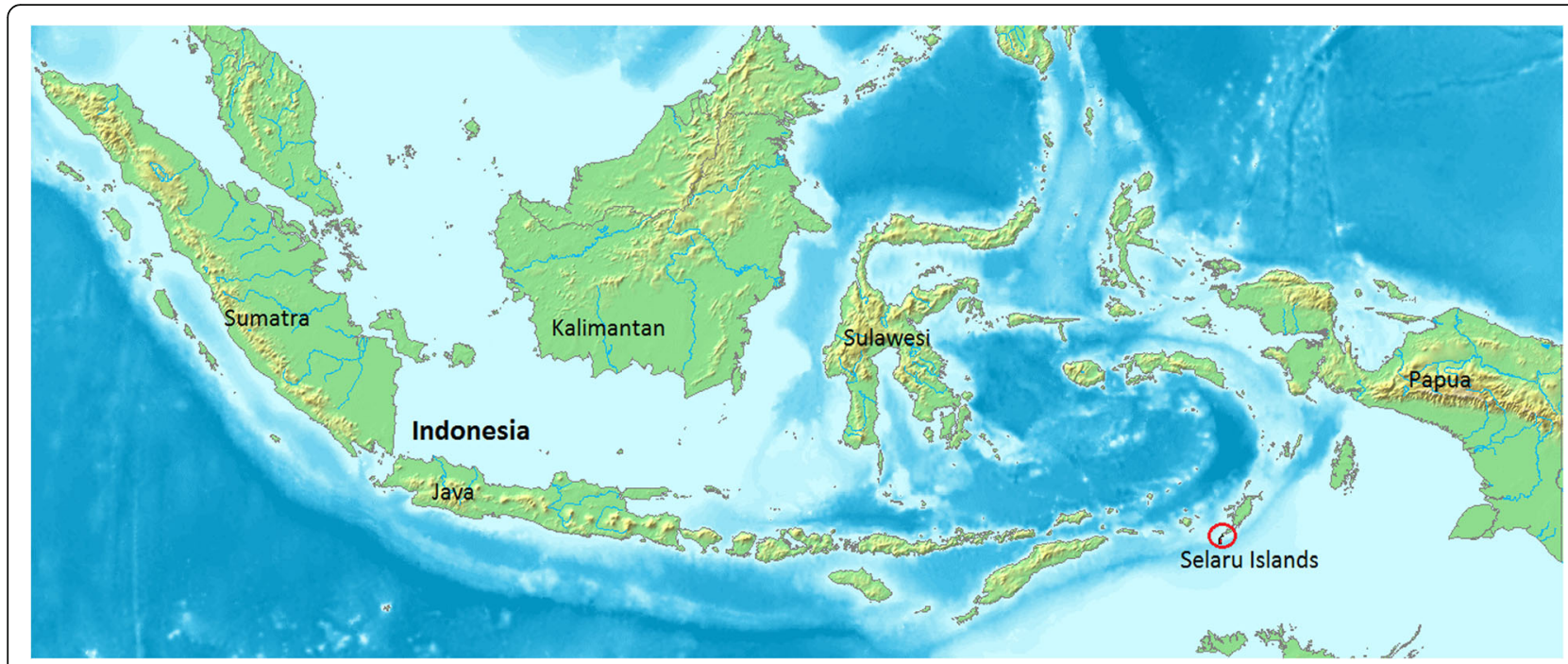

Fig. 1 Location of Selaru Island in Indonesia (Source: Wikimedia Commons)

in the past two years, under the age of 2 years, and suspect of having tuberculosis. The aim was to reach at least $80 \%$ of the population, because a high coverage is desired to break the transmission chain by sufficiently reducing the bacterial load of $M$. leprae in the population. The target was not achieved during the first visit because many people were away from their houses to earn livelihood. Therefore, the first (baseline) visit was extended with a second visit in November 2015 to cover the absentees of the first year visit. Individuals who had received SDR during the first visit were not re-examined for leprosy during the second visit. During the study period, SDR was given only once to an individual.

\section{Study infrastructure}

During the first visit, two teams were formed, each led by a medical doctor and supported by $2-3$ leprosy health workers. The mode of transportation was speed motor boats, leaving from Saumlaki (the capital of the district) and sailing for $3 \mathrm{~h}$ to reach Lingat village. Each visit lasted 5-6 days. However, the number of teams was

Table 1 Feasibility criteria for a blanket approach campaign

\begin{tabular}{ll}
\hline Criteria & Desired Eligibility \\
\hline Geographical location & Remote Island \\
The degree of isolation & $\begin{array}{l}\text { More than } 80 \% \text { of the community members } \\
\text { can be considered as contacts }\end{array}$ \\
Leprosy endemicity & $\mathrm{CDR}^{\mathrm{a}}>100 / 100,000$ \\
Sociocultural conditions & Openness for outsiders \\
Logistics and information & $\begin{array}{l}\text { Mode of transportation, best time to visit } \\
\text { as per weather conditions }\end{array}$ \\
Sustainability & The availability and training of health worker(s) \\
& to continue providing leprosy services
\end{tabular}

${ }^{a} C D R$ Case Detection Rate increased to five and six for the second and third visits. The details of the implementation process for all three visits are presented in Table 2.

A standard set of data were collected on paper forms, and later entered electronically. An additional file shows this in more detail (see Additional file 1). The demographical and clinical data were used for the descriptive analysis and assessment of the project coverage and epidemiological situation.

\section{Statistical analysis}

Data were subsequently entered into an excel-based electronic database during the visits. A unique identification number was generated for all personal records and matched to identify any previous contacts receiving SDR, but who later proved to be a leprosy case. Furthermore, contacts of the first and second visits were matched to check for overlap, because the second visit aimed to cover only those who missed the screening and SDR during the first visit. Data cleaning included assessment of missing values and logic checks for the related variables, e.g., age and dosage of rifampicin. Frequency distributions and subgroup analyses were performed for descriptive analysis. Groups were formed based on sex, age, type of leprosy and disability grade.

\section{Results}

The officially registered population of the island in November 2014 was 1900 , which increased to 2065 by November 2016. During the first two visits, 1743 (92\%) of this estimated population were listed, 1671 (88\%) screened, and 1499 (79\%) received SDR. The screening covered 1241 people during the first visit, the remaining 
Table 2 Standard steps followed while implementing the blanket approach

\begin{tabular}{|c|c|}
\hline Steps & Details \\
\hline 1. Communication & $\begin{array}{l}\text { Officially inform the local stakeholders about the } \\
\text { blanket approach and schedule }\end{array}$ \\
\hline $\begin{array}{l}\text { 2. Planning and } \\
\text { logistics }\end{array}$ & $\begin{array}{l}\text { - Training of the team } \\
\text { - - Arrangements for transportation, medicines, } \\
\text { supplies and stationary }\end{array}$ \\
\hline 3. Travel & A courtesy call to the village head \\
\hline 4. IEC & $\begin{array}{l}\text { Community information on health, leprosy and } \\
\text { purpose of visit }\end{array}$ \\
\hline 5. Screening & $\begin{array}{l}\text { Door to door: } \\
\text { - Line listing } \\
\text { - Informed consent } \\
\text { - Physical examination to diagnose leprosy } \\
\text { - - Checking eligibility criteria }\end{array}$ \\
\hline $\begin{array}{l}\text { 6. Medication/ } \\
\text { Referral }\end{array}$ & $\begin{array}{l}\text { - MDT to the newly identified cases } \\
\text { - SDR to the eligible individuals } \\
\text { (only in the first two visits) } \\
\text { - - Biological sample collection for difficult } \\
\text { to diagnose cases }\end{array}$ \\
\hline 7. Data collection & Simultaneously with step 5 and 6 \\
\hline $\begin{array}{l}\text { 8. Training of local } \\
\text { health worker }\end{array}$ & $\begin{array}{l}\text { - MDT treatment } \\
\text { - Management of leprosy complications } \\
\text { - - Follow-up of those who are absent or excluded } \\
\text { to receive SDR }\end{array}$ \\
\hline
\end{tabular}

430 people during the second visit, and 1481 people during the third visit (Table 3 ).

In the first two visits, the male-female ratio of those screened and receiving SDR was nearly $1: 1$. In total, 43 (2.6\%) persons were diagnosed with leprosy with the rate of 2263 per 100,000 population $(n=1900)$, of whom 16 (37\%) were female. During the third visit, 10 persons were diagnosed with leprosy at the rate of 484 per 100,000 population $(n=2065)$, with equal distribution of cases by gender.
Table 4 shows the number of people screened and detected with leprosy by age group. In all the visits, children in the age 2-14 years formed the largest group, followed by adults aged 25-49 years, and adults above 50 years. In total 43 new leprosy cases (2.57\%; 95\% CI: 1.84-3.36\%) were detected during the first two visits. Prevalence of leprosy was highest in those aged 15-24 years and 25-49 years (4.7 and $4.6 \%$, respectively). During the third visit, 10 new leprosy cases (0.68\%; 95\% CI: $0.35-1.29 \%)$ were detected and treated. The incidence was again high in the age group of 25-49 years (70\% cases).

In the first two visits, 14 of the cases had MB leprosy (33\%; 95\% CI: 19-47\%), and 29 PB leprosy (67\%; 95\% CI: $53-82 \%)$. Two people (5\%; 95\% CI: $-2.18-6.18 \%)$ had grade 2 disability. In the third visit, 6 cases had MB leprosy (60\%; 95\% CI: $27-86 \%$ ) out of 10 new cases, with no grade 2 disability (Table 5 ).

During the first two visits, SDR was administered to 1499 persons. Out of the total number screened who had no signs or symptoms of leprosy, 213 were excluded on the basis of the exclusion criteria (Table 6). Being absent and under 2 years of age were the most common reasons for exclusion. During the third visit, 1481 people were screened, of whom 1071 had received SDR during the earlier visits and 410 had not because of exclusion criteria or absence. The number of new cases among the 1071 who had received SDR was 6 and the number of cases among the 410 who had not received SDR was 4 (Table 7). The odds ratio is 0.57 (95\% CI: 0.16-2.03), indicating that the odds of having leprosy are lower in the exposed (SDR) than in the non-exposed (no SDR) group.

\section{Discussion}

The blanket approach in Lingat Village was implemented under the Leprosy Post Exposure Prophylaxis (LPEP) programme. The aim of LPEP is to assess impact and

Table 3 The number of individuals listed (males and females), screened, found with leprosy, and given SDR

\begin{tabular}{|c|c|c|c|c|c|c|}
\hline Visit & Sex & Listed & Screened & Leprosy & Prevalence (\% screened) & SDR \\
\hline \multirow[t]{3}{*}{ Survey 1 (2014) } & Male & 621 & 589 & 17 & $2.9 \%$ & 520 \\
\hline & Female & 668 & 652 & 12 & $1.8 \%$ & 584 \\
\hline & Sub total & 1289 & 1241 & 29 & $2.3 \%$ & 1104 \\
\hline \multirow[t]{3}{*}{ Survey 2 (2015) } & Male & 232 & 214 & 10 & $4.7 \%$ & 194 \\
\hline & Female & 222 & 216 & 4 & $1.9 \%$ & 201 \\
\hline & Sub total & 454 & 430 & 14 & $3.3 \%$ & 395 \\
\hline \multirow{2}{*}{\multicolumn{2}{|c|}{ Total (population 1900 in 2014) }} & $1743(92 \%)$ & $1671(88 \%)$ & 43 & $2.6 \%$ & $1499(79 \%)$ \\
\hline & & & & & Incidence & \\
\hline \multirow[t]{2}{*}{ Survey 3 (2016) } & Male & 954 & 717 & 5 & $0.7 \%$ & NA \\
\hline & Female & 1000 & 764 & 5 & $0.7 \%$ & \\
\hline \multicolumn{2}{|c|}{ Total (population 2065 in 2016) } & 1954 (95\%) & $1481(72 \%)$ & 10 & $0.7 \%$ & \\
\hline
\end{tabular}

The population was increased by the 3rd survey, which also included new individuals 
Table 4 Number of cases screened and detected with leprosy in different age groups

\begin{tabular}{|c|c|c|c|c|c|c|c|c|c|}
\hline \multirow[b]{2}{*}{ Age group in years } & \multicolumn{3}{|c|}{ Survey 1 (2014) } & \multicolumn{3}{|c|}{ Survey 2 (2015) } & \multicolumn{3}{|c|}{ Survey 3 (2016) } \\
\hline & Screened & Leprosy & Prevalence \% & Screened & Leprosy & Prevalence \% & Screened & Leprosy & Incidence \% \\
\hline Under 2 & 66 & 0 & 0 & 5 & 0 & 0 & 48 & 0 & 0.0 \\
\hline $02-14$ & 514 & 8 & 1.6 & 164 & 1 & 0.6 & 469 & 3 & 0.6 \\
\hline $15-24$ & 100 & 3 & 3 & 49 & 4 & 8.2 & 142 & 0 & 0.0 \\
\hline $25-49$ & 297 & 12 & 4 & 119 & 7 & 5.9 & 449 & 7 & 1.6 \\
\hline$\geq 50$ & 264 & 6 & 2.3 & 93 & 2 & 2.2 & 373 & 0 & 0.0 \\
\hline Total & 1241 & 29 & 2.3 & 430 & 14 & 3.3 & 1481 & 10 & 0.7 \\
\hline
\end{tabular}

feasibility of contact tracing and administration of single dose of rifampicin (SDR) to asymptomatic contacts of leprosy cases in the six countries (India, Nepal, Myanmar, Sri Lanka, Tanzania, Indonesia) [23]. Indonesia however, is the only country where the blanket approach is applied. In the other countries SDR is provided to close contacts of leprosy patients only.

The objective of the blanket approach campaign was to survey the complete target population and provide all eligible individuals with SDR in one visit in a high endemic, isolated population. Because the desired coverage of more than $80 \%$ was not reached, it was decided to conduct a second visit in the next year to include those who were missed during the first visit. The inadequate coverage in the first visit was mainly due to lack of awareness in the population regarding leprosy and its consequences, although the officials and inhabitants were well informed prior to the visit (Table 2). The absentees were out to earn livelihood, because there were wage losses when staying at home in receiving the intervention. The skin examination can only be done in daylight, therefore late evening or early morning timings were not suitable, although this could increase the

Table 5 PB-MB and G2D distribution according to sex in leprosy cases identified during three visits

\begin{tabular}{lllllllll}
\hline Visit & Sex & Leprosy & MB & $\%$ & PB & $\%$ & G2D & $\%$ \\
\hline Cases (2014) & Male & 17 & 8 & 47 & 9 & 53 & 2 & 12 \\
& Female & 12 & 4 & 33 & 8 & 66 & 0 & 0 \\
& Sub total & 29 & 12 & 41 & 17 & 59 & 2 & 12 \\
Cases (2015) & Male & 10 & 0 & 0 & 10 & 100 & 0 & 0 \\
& Female & 4 & 2 & 50 & 2 & 50 & 0 & 0 \\
& Sub total & 14 & 2 & 14 & 12 & 86 & 0 & 0 \\
Total & & 43 & 14 & 33 & 29 & 67 & 2 & 5 \\
Cases (2016) & Male & 5 & 3 & 60 & 2 & 40 & 0 & 0 \\
& Female & 5 & 3 & 60 & 2 & 40 & 0 & 0 \\
& Sub total & 10 & 6 & 60 & 4 & 40 & 0 & 0 \\
\hline \multirow{2}{*}{ Grand Total } & & 53 & 20 & 38 & 33 & 62 & 2 & 4 \\
\hline
\end{tabular}

coverage. Certainly, the first visit increase awareness, and the second visit emphasized seriousness of the intervention, which helped to increase the coverage in the following visits. By the end of second visit, 92\% were listed and $88 \%$ were screened. A third (follow-up) visit after a year was conducted to monitor the number of new cases arising in the population after the intervention during the two baseline visits. Among the people screened during the third visit, there was an apparent reduction of leprosy of around 50\% among those who had previously received SDR compared to those who had not. However, a high rate of transmission is evident as 3 child cases (2-14 age group) were detected in the third visit, and 2 of them had SDR in the previous visits. Studies on effectiveness have been done before, but not always with clear conclusions, due to methodological shortcomings. In 1988, a non-controlled trial with SDR $25 \mathrm{mg} / \mathrm{kg}$ dose was implemented in the Southern Marquesas Islands [24-26]. The intervention achieved 98.7\% coverage (2715 received SDR out of 2786 inhabitants), and additionally covered 3144 South Marquesans living elsewhere in French Polynesia. As a result, new 5 cases were detected in the next 10 years among treated population, which was significantly less than the 17 expected cases in a hypothetical situation of unchanged transmission rate. In comparison to the Polynesian population that did not receive the intervention, chemoprophylaxis was found to have an additional protective effect of 35-40\%. In 1990, Pacific islands implemented chemoprophylaxis in the Federated States of Micronesia, Kiribati and the Republic of the Marshall Islands [27]. The screening covered $70 \%$ of the population for two consecutive years, including chemoprophylaxis (both years) of rifampicin-ofloxacin-minocycline (ROM) to adults and rifampicin only to children under 15 years of age [28]. By 1999 a substantial reduction in case detection was observed, but it could not be established that this was due to intervention [27].

In the year 2000, five high endemic islands in Indonesia piloted chemoprophylaxis with a defined control group [22] with $600 \mathrm{mg}$ rifampicin for adults and $300 \mathrm{mg}$ for 
Table 6 Number and Reasons for Exclusion from SDR in the first two visits

\begin{tabular}{|c|c|c|c|c|c|c|c|c|}
\hline Visit & Absent & Refused Consent & Pregnant & Suspect Leprosy & Rifampicin History & Under age 2 & Suspect TB & Total \\
\hline Contact (2014) & 48 & 0 & 13 & 11 & 7 & 66 & 12 & 157 \\
\hline Contact (2015) & 24 & 0 & 5 & 11 & 4 & 5 & 7 & 56 \\
\hline Total & 72 & 0 & 18 & 22 & 11 & 71 & 19 & 213 \\
\hline
\end{tabular}

children (6-14 years old) with approximately 3.5 months between doses. Two types of chemoprophylactic intervention strategies (blanket approach and contact tracing SDR) were compared with a control group (no chemoprophylaxis). In contact tracing SDR, prophylaxis was given to eligible contacts of all known and newly found leprosy patients only, unlike the blanket approach. The population cohort of 3965 persons was actively screened before the intervention and subsequently once a year for three years. The yearly incidence rate in the control group was 39/10,000; the cumulative incidence after three years was significantly lower in the blanket group. No difference was found between the contact tracing SDR and the control groups. This study showed that population-based prophylaxis was associated with a reduced leprosy incidence in the first three years after implementation. Subsequently the COLEP trial in Bangladesh, in which SDR was given to contacts of leprosy patients, showed an overall reduction in the incidence of leprosy in the first two years of $57 \%$ [22]. The initial protective effect was maintained, but no difference in incidence was seen between the placebo and rifampicin groups beyond two years $[22,29,30]$.

Based on the preceding studies, it can be expected that the provision of chemoprophylaxis in a blanket approach to a well-defined highly endemic population will help reduce the transmission of $M$. leprae in that population. Apart from overall reduction of leprosy cases in the coming years, we do expect a possible relative increase

Table 7 The details of new cases detected in the third visit

\begin{tabular}{lllll}
\hline SDR history & SDR in visit & Age & Gender & Type \\
\hline Received & 1st & 3 & M & PB \\
Received & 2nd & 5 & M & PB \\
Received & 1 st & 25 & M & MB \\
Received & 1 st & 27 & F & MB \\
Received & 1st & 44 & M & PB \\
Received & 1st & 49 & F & MB \\
Not received & NA & 4 & M & MB \\
Not received & NA & 32 & F & PB \\
Not received & NA & 33 & F & PB \\
Not received & NA & 49 & F & MB \\
\hline
\end{tabular}

NA Not applicable in $\mathrm{MB}$ cases because $\mathrm{SDR}$ is more effective in reducing the $\mathrm{PB}$ cases due to lower bacterial load than MB. The increase in $\mathrm{MB}$ cases can also be due to previously missed early $\mathrm{MB}$ cases as it is often difficult to diagnose such cases through screening. One can expect that potential $\mathrm{MB}$ and $\mathrm{PB}$ cases that are early in the incubation period may respond well to SDR, but not those $\mathrm{MB}$ cases which are already advanced in their clinical stage. There are however, several important remaining questions regarding implementation aspects of such approach, and on the intensity and duration of active follow-up. It cannot be expected that leprosy will disappear by itself after a one-off intervention, as the experience of the Federated States of Micronesia and the Marshall Islands sadly demonstrated. The current study in Lingat village showed that the campaign could not be completed in just one visit. In order to optimize the effect of such campaign, an effort should be made to reach as much people in a single first round or to leave limited time between the first and second round, to avoid unidentified leprosy patients continuing to spread M. leprae in their surroundings. A one-year intercept is already quite long, and it would be preferable to conduct the second round within 6 months.

\section{Conclusion}

The study in Lingat village shows that the blanket approach is in principal operationally feasible in terms of staff and time investment. It could likely be implemented in similar locations and sociocultural settings. The population preparation (prior information on timelines, methods and objectives of survey) is crucial in attaining the desired coverage. The people generally showed no resistance to the intervention and mostly accepted the SDR without refusal of consent. Most individuals excluded from SDR had genuine contraindications for receiving SDR. The intervention achieved a good balance in reaching males and females. The number of child cases was high (21\%), indicating active transmission of $M$. leprae in the community. We recommend a close monitoring of children in the future, especially the under 2 years group, which was excluded from receiving SDR in the campaign. Furthermore, the intervention covered a relatively large group of children, probably because this group stays at home during the day, compared to other household members who are often out working. 
So far, SDR appeared to show protective effect against leprosy during the third visit. We recommend to conduct a fourth visit in Lingat village after one year to re-screen the full population, so that the effectiveness of the SDR can be further established. There is no evidence yet regarding the number of rounds required to control or eliminate leprosy is such setting, and the desired time interval between rounds. Because we expect to find more leprosy cases in future, contingency plans need to be made to actively follow this village closely in the coming years and continue leprosy elimination efforts until no new cases are found any more.

\section{Additional file}

Additional file 1: Type of data collected during the visits of blanket campaign. Type of data collected during the visits of blanket campaign. (DOCX $13 \mathrm{~kb}$ )

\section{Abbreviations}

G2D: Grade II Disability; LPEP: Leprosy Post Exposure Prophylaxis; MB: Multibacillary; MDT: Multidrug therapy; NLCP: National Leprosy Control Programme; PB: Paucibacillary; PEP: Post-exposure prophylaxis; ROM: Rifampicin-Ofloxacin-Minocycline; SDR: Single dose of rifampicin

\section{Acknowledgements}

We would like to thank the staff of the National Leprosy Control Programme, Indonesia, Maluku provincial and Maluku Tenggara Barat District Health Office and NLR Indonesia for conducting the blanket approach under difficult circumstances. The scientific advice was provided by the LPEP study group.

\section{Funding}

This paper is written as a part of Leprosy Post-Exposure prophylaxis program, funded by Novartis Foundation. There was no role of the funding body in designing the study, data collection, and analysis.

\section{Availability of data and materials}

The datasets used and/or analysed during the current study are available from the corresponding author on reasonable request from Subdirectorate Tropical Disease of Leprosy and Yaws, Ministry of Health Indonesia.

\section{Authors' contributions \\ AT, SD, LM, JHR conceived the study. SD, RD, LM were responsible for planning and carrying out the field work. AT, SD, RD, LM and JHR monitored data quality. AT analysed the data and prepared first draft of the manuscript, and JHR supervised the work. AT prepared the original draft and SD, RD, LM, JHR edited and revised the manuscript. All authors read and approved the final manuscript. AT and SD contributed equally to the study, therefore should be regarded as joint First Authors.}

\section{Ethics approval and consent to participate}

Ethics approval not applicable. Post exposure prophylaxis with single dose of rifampicin is a routine strategy under National Leprosy Control Program (NLCP) of Indonesia. The study was conducted as a routine monitoring and evaluation activity of NLCP. A verbal consent was taken from all the participants, and from parents in case of minors. The information on refused consent is shown in Table 6.

\section{Consent for publication}

A verbal consent was taken from all the participants and data on declined consent were reported in the result section.

\section{Competing interests}

The authors declare that they have no competing interests.

\section{Publisher's Note}

Springer Nature remains neutral with regard to jurisdictional claims in published maps and institutional affiliations.

\section{Author details}

${ }^{1}$ Department of Public Health, Erasmus MC, University Medical Center Rotterdam, P.O.Box 2040, 3000, CA, Rotterdam, The Netherlands.

${ }^{2}$ Netherlands Leprosy Relief, Jakarta, Indonesia. ${ }^{3}$ Subdirectorate Tropical Disease of Leprosy and Yaws, Ministry of Health Indonesia, Jakarta, Indonesia. ${ }^{4}$ Netherlands Leprosy Relief, Amsterdam, The Netherlands.

Received: 21 September 2017 Accepted: 3 July 2018

Published online: 11 July 2018

\section{References}

1. Rinaldi A. The global campaign to eliminate leprosy. PLoS Med. 2005;2:e341.

2. Bennett BH, Parker DL, Robson M. Leprosy: steps along the journey of eradication. Public Health Rep. 2008;123:198-205.

3. Daumerie D. Elimination of leprosy as a public health problem — current status and challenges ahead, Scientific Working Group Report on leprosy: World Health Org; 2003. http://www.who.int/lep/resources/SWG04.pdf. Accessed 13 Oct 2015.

4. Fine PEM. Leprosy: what is being "eliminated"? Bull World Health Organ. 2007:85:2. https://doi.org/10.2471/Blt.06.039206.

5. Global leprosy update, 2015: time for action, accountability and inclusion. Wkly Epidemiol Rec. 2016;91:405-20.

6. World Health Organization. Global Leprosy Programme. http://www. searo.who.int/entity/global_leprosy_programme/leprosy_as_a_disease/ en/. Accessed 16 June 2016.

7. Central Bureau of Statistics. Indonesian Population by Province. 2012. https:// www.bps.go.id/linkTabelStatis/view/id/1267. Accessed 19 Apr 2016.

8. Central Bureau of Statistics. Percentage of Urban Population by Province 2010-2035, Indonesia. https://www.bps.go.id/linkTabelStatis/ view/id/1276. Accessed 19 Apr 2016.

9. The Indonesian Health Care System. Reducing Maternal and Neonatal Mortality in Indonesia: Saving lives, saving the future. Washington: National Academies Press (US); 2013. p. 39-52.

10. Global leprosy update, 2014: need for early case detection. Wkly Epidemiol Rec. 2015(90):461-74.

11. Blok DJ, De Vlas SJ, Richardus JH. Global elimination of leprosy by 2020: are we on track? Parasit Vectors. 2015:8:548.

12. Uniting to Combat NTDs. Country Leadership and Collaboration on Neglected Tropical Diseases: Third progress report of the London Declaration.. http://unitingtocombatntds.org/sites/default/files/document/ UTCNTD\%20FULL\%20REPORT.pdf Accessed 9 Apr 2016.

13. World Health Organization. Accelerating Work to Overcome the Global Impact of Neglected Tropical Diseases: A Roadmap for Implementation. 2012. http://www.who.int/neglected_diseases/NTD_RoadMap_2012_ Fullversion.pdf?ua=1. Accessed 16 June 2016.

14. WHv B, Sihombing B, Djarir H, Beise K, Kusumawardhani L. Disability in people affected by leprosy: the role of impairment, activity, social participation, stigma and discrimination. Glob Health Action. 2012;5. https:// doi.org/10.3402/gha.v5i0.18394.

15. Anastasia I. The Wall Street Journal. Leprosy Cases Decline in Indonesia, but Not Stigma. 2015. http://blogs.wsj.com/ indonesiarealtime/2015/01/27/leprosy-cases-decline-in-indonesia-butnot-stigma/. Accessed 9 Apr 2016.

16. Lusli M, Zweekhorst MBM, Miranda-Galarza B, Peters RMH. Dealing with stigma: experiences of persons affected by disabilities and leprosy. Biomed Res Int. 2015;2015:1-9.

17. Gelber RH, Grosset J. The chemotherapy of leprosy: an interpretive history. Lepr Rev. 2012;83:221-40.

18. Global Leprosy Strategy 2016-2020: Accelerating towards a leprosy-free world. 2016. http://www.searo.who.int/entity/global_leprosy_programme/ documents/global_leprosy_strategy_2020/en/. Accessed 08 July 2018.

19. Richardus JH, Oskam L. Protecting people against leprosy: chemoprophylaxis and immunoprophylaxis. Clin Dermatol. 2015;33:19-25.

20. Smith WC, Aerts A. Role of contact tracing and prevention strategies in the interruption of leprosy transmission. Lepr Rev. 2014;85:2-17.

21. Louhenapessy AA, Zuiderhoek B. A practical method of active case finding and epidemiological assessment: its origin and application in the leprosy control project in Indonesia. Int J Lepr Other Mycobact Dis. 1997;65:487-91. 
22. Bakker Ml, Hatta M, Kwenang A. Prevention of leprosy using rifampicin as chemoprophylaxis. Am J Trop Med Hyg. 2005;72:443-8.

23. Barth-Jaeggi T, Steinmann P, Mieras L, van Brakel W, Richardus JH, Tiwari A, et al. Leprosy post-exposure prophylaxis (LPEP) programme: study protocol for evaluating the feasibility and impact on case detection rates of contact tracing and single dose rifampicin. BMJ Open. 2016;6:e13633.

24. Cartel JL, Chanteau S, Boutin JP, Taylor R, Plichart R, Roux J, et al. Implementation of chemoprophylaxis of leprosy in the southern Marquesas with a single dose of $25 \mathrm{mg}$ per $\mathrm{kg}$ rifampin. Int J Lepr Other Mycobact Dis. 1989;57:810-6.

25. Cartel JL, Chanteau S, Moulia-Pelat JP, Plichart R, Glaziou P, Boutin JP, et al. Chemoprophylaxis of leprosy with a single dose of $25 \mathrm{mg}$ per $\mathrm{kg}$ rifampin in the southern Marquesas; results after four years. Int J Lepr Other Mycobact Dis. 1992;60:416-20.

26. Nguyen LN, Cartel JL, Grosset JH. Chemoprophylaxis of leprosy in the southern Marquesas with a single $25 \mathrm{mg} / \mathrm{kg}$ dose of rifampicin. Results after 10 years. Lepr Rev. 2000;71 Suppl:S33-5. discussion S5-6

27. Blanc LJ. Summary of leprosy chemoprophylaxis programs in the western Pacific region. Int J Lepr Other Mycobact Dis. 1999;67:S30-1.

28. Diletto C, Blanc L, Levy L. Leprosy chemoprophylaxis in Micronesia. Lepr Rev. 2000;71 Suppl:S21-3. discussion S4-5

29. FJ M, Pahan D, Oskam L, Richardus JH, Group CS. Effectiveness of single dose rifampicin in preventing leprosy in close contacts of patients with newly diagnosed leprosy: cluster randomised controlled trial. BMJ. 2008;336: 761-4. https://doi.org/10.1136/bmj.39500.885752.BE.

30. Feenstra SG, Pahan D, Moet FJ, Oskam L, Richardus JH. Patient-related factors predicting the effectiveness of rifampicin chemoprophylaxis in contacts: 6 year follow up of the COLEP cohort in Bangladesh. Lepr Rev. 2012;83:292-304

Ready to submit your research? Choose BMC and benefit from:

- fast, convenient online submission

- thorough peer review by experienced researchers in your field

- rapid publication on acceptance

- support for research data, including large and complex data types

- gold Open Access which fosters wider collaboration and increased citations

- maximum visibility for your research: over $100 \mathrm{M}$ website views per year

At BMC, research is always in progress.

Learn more biomedcentral.com/submissions 